Open Access

\title{
Interaction between buyer power in agricultural procurement and seller power in food retailing, and optimal allocation of anti-trust efforts
}

Tian Xia* (D) and Brian Sancewich

* Correspondence: tianxia@ksu.edu Kansas State University, Manhattan, KS, USA

\begin{abstract}
In order to take appropriate and effective actions against anticompetitive behaviors in the agricultural sector, it is essential to understand the interaction between buyer power in agricultural procurement and seller power in food retailing and the optimal allocation of anti-trust efforts between markets to maximize welfare. This paper finds that, even if the policy objective is to maximize farmer welfare, anti-trust efforts may need to put to both farm and retail markets. More importantly, the optimal allocations of anti-trust efforts are the same for three different policy objectives: to maximize farmer welfare, to maximize consumer welfare, and to maximize social welfare. The steepness of farm supply and consumer demand curve, along with processors' buyer power and retailers' seller power, can affect the optimal allocation of anti-trust efforts. Some guidelines and formula are suggested for designing optimal allocation of anti-trust efforts between farm and retail markets.
\end{abstract}

\section{Background}

Two forms of market power along food market chain that have received significant attention are wholesalers'/processors' buyer power in agricultural procurement and retailers' seller power in food retailing. These two forms of market power have important implications for agricultural producers and consumers. In agricultural procurement, many US industries, such as livestock, dairy, soybeans, poultry, and seed, have become more and more concentrated in the recent decades. For example, the four-firm concentration ratio (CR4) in beef packing increased from 36\% in 1980 to 85\% in 2015 (U.S. Department of Agriculture, Grain Inspection Packers and Stockyards Administration 2016), and the national CR4 of fluid milk processing grew from 16\% in 1982 to 43\% in 2002 (U.S. Department of Agriculture, Economic Research Service 2007). This increasing concentration has made producers, policymakers, and academic researchers to be concerned about the anticompetitive effects of potential buyer power in agricultural procurement on farm price and producer welfare. Academic studies and government reports have focused on concentration and buyer power issues. Buyer power has been analyzed in the markets of many agricultural and food products including wheat (Stiegert and Hamilton

(c) The Author(s). 2018 Open Access This article is distributed under the terms of the Creative Commons Attribution 4.0 International License (http://creativecommons.org/licenses/by/4.0/), which permits unrestricted use, distribution, and reproduction in any medium, provided you give appropriate credit to the original author(s) and the source, provide a link to the Creative Commons license, and indicate if changes were made. 
1998), cattle (Azzam and Anderson 1996; McEowen et al. 2002; Ward 2002), hogs (Zheng and Vukina 2009), milk (Alvarez et al. 2000), cocoa (Wilcox and Abbott 2006), tobacco (Raper et al. 2000), and tomatoes (Durham and Sexton 1992; Huang and Sexton 1996).

Another form of market power is seller power in food retailing. In food retail markets, given the increasing concentration, spatial distribution of consumers and stores, and store differentiation, food retailers may be able to use seller market power to influence prices charged to consumers. The national CR4 in food retailing increased from $16.8 \%$ in 1992 to $37.3 \%$ in 2011, and the average local CR4 in metropolitan areas was 72.3\% in 2007 (U.S. Department of Agriculture, Economic Research Service 2007; 2012). Spatial distribution of consumers and retail stores allows a store to have market power over the consumers in vicinity (Benson and Faminow 1985; Walden 1990; Azzam 1999). Differentiated pricing and marketing strategies adopted by retailers may also improve their ability to influence retail prices (Varian 1980; Lal and Rao 1997; Pesendorfer 2002; Sexton et al. 2003; Boatwright et al. 2004; Hosken and Reiffen 2004; Davis 2010; Volpe 2013). Market power and structure issues in agricultural procurement and food retailing in other countries are also examined and discussed in studies such as Declerck et al. (1999) on French beef industry, Farina et al. (2004) on Brazilian supermarket chains, Lloyd et al. (2009) on the UK food sector, and Digal (2010) on the Philippine poultry industry.

In 2010, the Antitrust Division of the US Department of Justice and the US Department of Agriculture held the first-ever joint public workshops on competition issues in the agricultural sector including the two forms of market power: buyer power in agricultural procurement and seller power in food retailing. A report on the workshops issued by the US Department of Justice indicates that "These discussions (from the workshops) confirmed that a healthy agricultural sector requires competition and, consequently, vigorous anti-trust enforcement." and says the workshops resulted in "an enhanced understanding of agricultural markets" and "a greater appreciation of how anticompetitive practices in these markets can harm producers and consumers." (U.S. Department of Justice 2012, p. 2).

In the model we develop in this study, when buyer power in agricultural procurement and seller power in food retailing coexist, the welfare gain to farmers or consumers through addressing one form of market power is usually reduced by the other form of market power in the supply chain. This observation suggests that tackling both forms of market power at the same time can be more effective for promoting competition and providing benefits to farmers and consumers. However, how should a policymaker optimally allocate anti-trust efforts between farm and retail markets in order to maximize welfare? When the policy objective is to maximize farmer welfare, should all or most anti-trust efforts be put in addressing market power issues in farm markets? Or a more general question is, for different policy objectives such as to maximize farmer welfare only, consumer welfare only, or total social welfare, should a policymaker adopt different optimal allocations of anti-trust efforts or use the same allocation? What factors and how do they affect the optimal allocation of anti-trust efforts across markets along the supply chain? The answers to these questions would be very helpful for policymakers to take effective actions against anticompetitive behaviors in the agricultural sector and 
improve the understanding on the optimal allocation of anti-trust efforts along the food market chain.

Some previous research has included market power in two stages, buyer power in agricultural procurement and seller power in finished product sales, in an integrated economic framework (Schroeter 1988; Azzam and Pagoulatos 1990; Alston et al. 1997; Sexton 2000). ${ }^{1}$ But all those studies focus on different issues such as price distortions and impact on research benefits. Another related literature in economics is the one on double marginalization (Spengler 1950; Tirole 1988; Katz 1989), which analyzes sequential oligopoly/seller power (or sequential oligopsony/buyer power) in the upstream and downstream market. The vertical structure examined in this paper along the food market chain is a different one, where there is buyer power in the upstream (agricultural procurement) and seller power in the downstream (food retailing). No published research has examined (1) how a policymaker should optimally allocate anti-trust efforts between farm and retail markets under different policy objectives and (2) what factors and how they affect the optimal allocation of anti-trust efforts across markets along the supply chain.

In this paper, we use a simple framework to show that, even if the policy objective is to maximize farmer welfare only, anti-trust efforts may need to be allocated to both farm and retail markets. More importantly, the same optimal allocation of anti-trust efforts among markets should be used for these three different policy objectives: (i) to maximize farmer welfare, (ii) to maximize consumer welfare, and (iii) to maximize social welfare. The economic intuition is that reducing market power through anti-trust efforts in one market will also benefit the market participants in other markets so that a policymaker always allocates anti-trust efforts to make sure that the marginal gain in welfare due to putting anti-trust efforts in one market is equal to the marginal gain due to putting the efforts in another market, regardless of whether the objective is to maximize the welfare of farmers only, consumers only, or the entire society. Any optimal allocation of anti-trust efforts that maximizes farmer welfare should provide the largest increase in quantity sold by farmers. This means there will also be the largest increase in quantity purchased by consumers, which is associated with the maximum consumer welfare. There are also the largest increases in quantities transacted in all markets along the supply chain, which means deadweight loss is minimized and social welfare is maximized. Our analysis also shows what factors and how they affect the optimal allocation of anti-trust efforts, and provides guidelines to calculate the optimal shares of anti-trust efforts for farm and retail markets.

\section{Methods}

In the model, the market chain of an agricultural product consists of three stages: farm, wholesale, and retail markets. Farmers sell a raw agricultural material to wholesalers/ processors (hereafter "processors" in the model analysis) in the farm market. Then, processors trade the processed/finished product to food retailers through the wholesale market. Finally, consumers purchase the product from the retailers.

In the farm market, $M$ oligopsony processors procure the raw agricultural material from farmers, where the value of $M$ measures the degree of buyer power in the farm 
market with smaller values of $M$ indicating stronger buyer power. ${ }^{2}$ Inverse farm supply in a local market is specified as:

$$
P_{f}=a+b q_{f},
$$

where $P_{f}$ is the price farmers receive, $q_{f}$ is the quantity supplied in a farm market, $b>$ 0 and subscript " $f$ " denotes the farm market.

In the retail market, $N$ oligopoly food retailers sell the product to consumers. The value of $N$ is a measure of the degree of seller power in the retail market, and smaller values of $N$ represent stronger seller power. The inverse consumer demand function in a local retail market is:

$$
P_{r}=\lambda-\beta q_{r},
$$

where $P_{r}$ is the retail price, $q_{r}$ is the quantity demanded in the retail market, and $\beta>0$ and subscript " $r$ " denotes the retail market. Retailers have a constant average and marginal selling cost $C_{r}$.

Processors sell the processed product to food retailers in the wholesale market. Various market structure may exist in wholesale markets for agricultural and food products. For a discussion of food wholesale market structure, please see Phlips (1980), Azzam (1999), Schroeter et al. (2000), Richards and Patterson (2003), Sexton et al. (2003), Lloyd et al. (2009), and Draganska et al. (2010). In this paper, we use the case of a competitive wholesale market to facilitate the presentation of results. ${ }^{3}$

We follow Zhang and Sexton (2000) to use a fixed-portion production function and assume a constant average and marginal cost. Processors convert the raw agricultural material into the processed product according to a fixed-proportion production function. Through the choice of measurement unit, we can have $q_{w}=q_{f}$, where $q_{w}$ is the quantity of the wholesale product converted from the raw agricultural material of one farm market, and subscript $w$ denotes the wholesale market. The constant average and marginal wholesaling/processing cost is $C_{w}{ }^{4}$

Anti-trust efforts of the government are represented by $\bar{E}$. The efforts can be allocated between farm and retail markets according to

$$
\bar{E}=E_{f}(\Delta M)+E_{r}(\Delta N),
$$

where $E_{f}(\Delta M)$ is the amount of anti-trust efforts allocated to farm markets, which increases the farm market competition level by $\Delta M$, with $\partial E_{f} / \partial \Delta M>0$ and $E_{f}(0)=0$; $E_{r}(\Delta N)$ is the amount of anti-trust efforts allocated to retail markets, which increases the retail market competition level by $\Delta N$, with $\partial E_{r} / \partial \Delta N>0$ and $E_{r}(0)=0$.

We first derive the equilibrium prices and quantities of all markets along the food market chain. Then, based on the interaction between buyer power in agricultural procurement and seller power in food retailing, we derive the optimal allocation of anti-trust efforts between farm and retail markets for three policy goals and analyze what factors and how they affect the optimal allocation.

\section{The market equilibrium}

In this section, we derive the market equilibrium in each stage of the food market chain. Let us start with the retail market to find the market equilibrium. Given the wholesale price $P_{w}$, food retailer $n(n=1,2, \ldots, N)$ sells the optimal quantity $q_{r, n}$ 
of the finished product to consumers to maximize her profit $\pi_{n}=\left(P_{r}-P_{w}-C_{r}\right) q_{r, n}$. Having obtained and solved all $N$ first-order conditions simultaneously for the optimal quantities of retailers, the solutions are substituted back into the market-clearing condition $\left(\sum_{n=1}^{N} q_{r, n}=q_{r}=\left(\lambda-P_{r}\right) / \beta\right)$ to find the equilibrium price and quantity in a retail market, conditional on the wholesale price $P_{w}$ :

$P_{r}=[N /(N+1)]\left(P_{w}+C_{r}\right)+\lambda /(N+1)$ and $q_{r}=[N /(N+1)]\left(\lambda-P_{w}-C_{r}\right) / \beta$.

Using this conditional retail quantity $q_{r}$ and the wholesale demand $q_{w}=q_{r}$ we derive the corresponding inverse demand function in the wholesale market as:

$$
P_{w}=\lambda-C_{r}-[\beta(N+1) / N] q_{w} .
$$

Following the similar method, we also obtain the equilibrium price and quantity in the farm market, conditional on the wholesale price $P_{w}$ :

$P_{f}=[M /(M+1)]\left(P_{w}-C_{w}\right)+a /(M+1)$ and $q_{f}=[M /(M+1)]\left(P_{w}-C_{w}-a\right) / b$ and then find the inverse wholesale supply function as $P_{w}=a+C_{w}+[b(M+1) / M] q_{w}$.

We substitute the (conditional) equilibrium price and quantity of the retail market and the farm market, conditional on the wholesale price, into the wholesale market-clearing condition solve for $P_{w}$ to obtain the equilibrium wholesale price:

$$
P_{w}=\left[b N(M+1)\left(\lambda-C_{r}\right)+\beta M(N+1)\left(a+C_{w}\right)\right][b N(M+1)+\beta M(N+1)]^{-1} .
$$

The equilibrium wholesale price is increasing in the retail demand factor $(\lambda)$, the farm production parameter $a$, average wholesale cost $\left(C_{w}\right)$, and the competition level $(N)$ in retail markets and decreasing in average retail cost $\left(C_{r}\right)$ and the competition level $(M)$ in farm markets. Using this equilibrium wholesale price, we also find the unconditional equilibrium price in retail and farm markets: ${ }^{5}$

$$
P_{r}=\lambda-\beta M N\left(\lambda-C_{r}-C_{w}-a\right) /[b N(M+1)+\beta M(N+1)]
$$

and

$$
P_{f}=a+b M N\left(\lambda-C_{r}-C_{w}-a\right) /[b N(M+1)+\beta M(N+1)],
$$

and consumer surplus (CS) in the retail market, the farmers' producer surplus (PS), and total social welfare (SW) along the food market chain:

$$
\begin{aligned}
& \mathrm{CS}=(1 / 2) \beta M^{2} N^{2}\left(\lambda-C_{r}-C_{w}-a\right)^{2} /[b N(M+1)+\beta M(N+1)]^{2}, \\
& \mathrm{PS}=(1 / 2) b M^{2} N^{2}\left(\lambda-C_{r}-C_{w}-a\right)^{2} /[b N(M+1)+\beta M(N+1)]^{2},
\end{aligned}
$$

and

$\mathrm{SW}=\left[\left(\frac{M}{2}+1\right) b N+\left(\frac{N}{2}+1\right) \beta M\right] M N\left(\lambda-C_{r}-C_{w}-a\right)^{2} /[b N(M+1)+\beta M(N+1)]^{2}$.

The equilibrium retail price is increasing in the retail demand factor $(\lambda)$, the farm production parameter $(a)$, and average wholesale and retail cost $\left(C_{w}\right.$ and $\left.C_{r}\right)$ and decreasing in the competition level $(N)$ in retail markets and the competition level $(M)$ in farm markets. The equilibrium farm price is increasing in the retail demand factor $(\lambda)$, the farm production parameter $(a)$, and the competition level $(M)$ in farm markets and the competition level $(N)$ in retail markets and decreasing in the average wholesale and retail cost $\left(C_{w}\right.$ and $\left.C_{r}\right)$. Regarding the welfare measures, consumer surplus is decreasing in the steepness $(b)$ of farm supply curve, 
farmers' producer surplus is decreasing in the steepness $(\beta)$ of consumer demand curve, all welfare measures are increasing the retail demand factor $(\lambda)$, and decreasing in the farm production factor $(a)$, wholesale and retail cost, buyer power in farm markets, and seller power in retail markets.

Let $\delta_{w}$ denotes the processors' profit margin, which is the difference between the wholesale price $P_{w}$ and the sum $\left(P_{f}+C_{w}\right)$ of the farm price and marginal wholesaling cost. Similarly, retailers' profit margin $\delta_{r}$ is the difference between the retail price $P_{r}$ and the sum $\left(P_{w}+C_{r}\right)$ of the wholesale price and marginal retailing cost. Through the calculation based on the three equilibrium prices, we have the profit margins of processors and retailers in the first scenario as:

$$
\delta_{w}=b N\left(\lambda-C_{r}-C_{w}-a\right) /[b N(M+1)+\beta M(N+1)]
$$

and

$$
\delta_{r}=\beta M\left(\lambda-C_{r}-C_{w}-a\right) /[b N(M+1)+\beta M(N+1)] .
$$

\section{Allocation of anti-trust efforts}

In this section, we examine the optimal allocation of anti-trust efforts to achieve three specific welfare goals: (i) to maximize farmer welfare, (ii) to maximize consumer welfare, and (iii) to maximize social welfare. First, to maximize farmer welfare, a policymaker's maximization problem is:

$$
\begin{aligned}
& \operatorname{Max}_{E_{f}, E_{r}} \Delta \mathrm{PS} \\
& \text { s.t. } E_{f}+E_{r}=\bar{E},
\end{aligned}
$$

where $\Delta \mathrm{PS}$ is the gain in farmers' producer surplus due to the anti-trust efforts; $E_{f}$ and $E_{r}$ are the amount of the anti-trust efforts allocated to the farm and retail market, respectively, and $\bar{E}$ is the total amount of the available anti-trust efforts. We solve the constraint $E_{f}+E_{r}=E_{f}(\Delta M)+E_{r}(\Delta N)=\bar{E}$ for $\Delta N$ to obtain

$\Delta N=\Phi^{-1}(0)$,where $\Phi^{-1}(\bullet)$ is the inverse function of $\Phi(\bullet)$ and $\Phi(\Delta N)=\bar{E}-E_{r}(\Delta N)$ $-E_{f}(\Delta M)$ with $\partial \Phi / \partial \Delta M<0$ and $\partial \Phi / \partial \bar{E}>0$.

Using the solution of $\Delta N$ and the equilibrium result of farmers' producer surplus, we find the farmer welfare gain as:

$$
\begin{aligned}
\Delta \mathrm{PS} \approx(\partial \mathrm{PS} / \partial M) \Delta M & +(\partial \mathrm{PS} / \partial N) \Delta N \\
& =b M N\left[b N^{2} \Delta M+\beta M^{2} \Phi^{-1}(0)\right]\left(\lambda-C_{r}-C_{w}-a\right)^{2} \\
& /[b N(M+1)+\beta M(N+1)]^{3} .
\end{aligned}
$$

Solving the first-order condition $\partial \Delta \mathrm{PS} / \partial \Delta M=0$ for $\Delta M$ and substituting the solution of $\Delta M$ into the anti-trust effort equation yields the optimal allocation of anti-trust efforts as:

$$
E_{f}=E_{f}\left[\Psi^{-1}(0)\right]
$$

where $\Psi^{-1}(\bullet)$ is the inverse function of $\Psi(\bullet)$ and $\Psi(\Delta M)=b N^{2}+\beta M^{2}\left[\partial \Phi^{-1}(0) / \partial \Delta M\right]$ with $\partial \Phi^{-1}(0) / \partial \Delta M<0$ and $E_{r}=\bar{E}-E_{f}\left[\Psi^{-1}(0)\right]$.

Similarly, a policymaker's problem to maximize consumer welfare is: 


$$
\begin{aligned}
& \operatorname{Max}_{E_{f}, E_{r}} \Delta C S \\
& \text { s.t. } E_{f}+E_{r}=\bar{E},
\end{aligned}
$$

where $\Delta \mathrm{CS}$ is the gain in consumer surplus due to the anti-trust efforts. In order to maximize the total social welfare, a policymaker's problem becomes:

$$
\begin{aligned}
& \operatorname{Max}_{E_{f}, E_{r}} \Delta \mathrm{SW} \\
& \text { s.t. } E_{f}+E_{r}=\bar{E},
\end{aligned}
$$

where $\Delta \mathrm{SW}$ is the gain in social welfare due to the anti-trust efforts. For each of these two additional welfare goals, we also solve the policymaker's maximization problem to obtain the optimal allocation of anti-trust efforts between the farm and retail market (please see the "Appendix" section for detailed derivation and results).

\section{Results and Discussion}

Based on the above analysis, we obtain the effects of the interaction between buyer power in agricultural procurement and seller power in food retailing, and the optimal allocation of anti-trust efforts to maximize welfare. The results are summarized in the following four propositions.

\section{Welfare effects of weakening one form of market power}

The results in the first two propositions describe the welfare effects of weakening only one form of market power and how a portion of the benefit is captured by retailers or processors.

Proposition 1 Although farmer welfare and farm price will increase if buyer power in agricultural procurement is weakened, the magnitudes of these increases are reduced by retailers' seller power. In addition, the anticompetitive effect of retailers' seller power will be enlarged, i.e., retailers' profit margin will increase.

When retailers have stronger seller power in retail markets, the farmer welfare and farm price increases due to weakened buyer power in agricultural procurement will be smaller. The increase in retailers' profit margin will be larger.

\section{Proof Appendix.}

The economic intuition of Proposition 1 is as follows: Each processor chooses the optimal amount of the agricultural material to purchase where the marginal revenue (MR) equals the marginal cost. The marginal revenue is increasing in the wholesale price, regardless of the wholesale market structure. Retailers' seller power causes the wholesale demand to be lower and less elastic through a pivotal shift, ${ }^{6}$ which leads to a lower wholesale price and a lower marginal revenue (MR) for processors. Even when weakened buyer power in agricultural procurement results in a farm price increase, the lower MR for processors due to retailers' seller power causes processors to compete less aggressively in farm markets than they would when the retail market is competitive and, thus, reduces the amount of farm price increase. Farmer welfare, measured by producer surplus, is increasing in the farm price, ceteris paribus. Thus, when retailers' seller power reduces the magnitude of farm price increase, it also diminishes the amount of farm welfare gain. 
On the other hand, retailers with market power usually pass partially a wholesale price increase/decrease to consumers because they set their marginal revenue, not the retail price, equal their marginal cost. When weakened buyer power in agricultural procurement causes more wholesale supply and, thus, a decrease in the wholesale price, only a portion of this wholesale price decrease is passed to consumers through a retail price decrease. Therefore, retailers' profit margin, the difference between the wholesale price and the retail price, will increase.

The degree of retailers' seller power can affect the magnitudes of the effects described above. Stronger seller power in retail markets can cause an even lower wholesale price and MR for processors. Thus, processors compete even less aggressively so that the increases in farmer welfare and farm price are further smaller. Retailers with more seller power pass a smaller portion of a wholesale price decrease to consumers so that their profit margin increase is larger.

Figures 1 and 2 illustrate how the magnitude of farm price increases due to weakened buyer power in agricultural procurement is reduced by retailers' seller power, and how the anticompetitive effect of retailers' seller power will be enlarged when buyer power in agricultural procurement is weakened. In the two figures, the parameter values are set as $a=2, b=1.1, \lambda=120$, and $\beta=0.9$. Buyer power in agricultural procurement is weakened from $M=2$ to $M=3$. Figure 1 shows that, compared with the case of perfect competition in retail markets, the magnitude of farm price increases due to weakened buyer power in agricultural procurement is reduced by retailers' seller power, and the reduction is larger when retailers' seller power is stronger. Figure 2 illustrates that retailers' profit

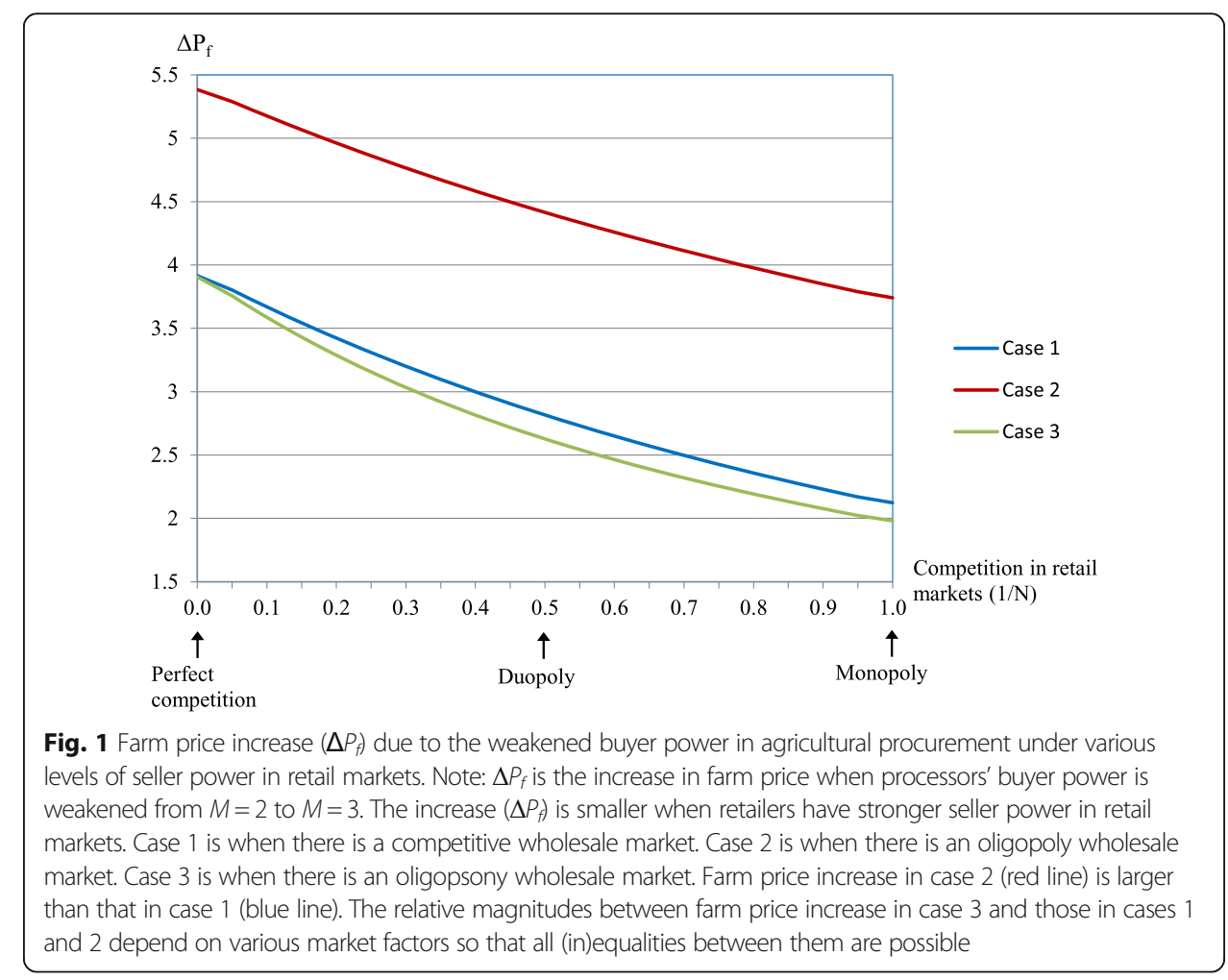




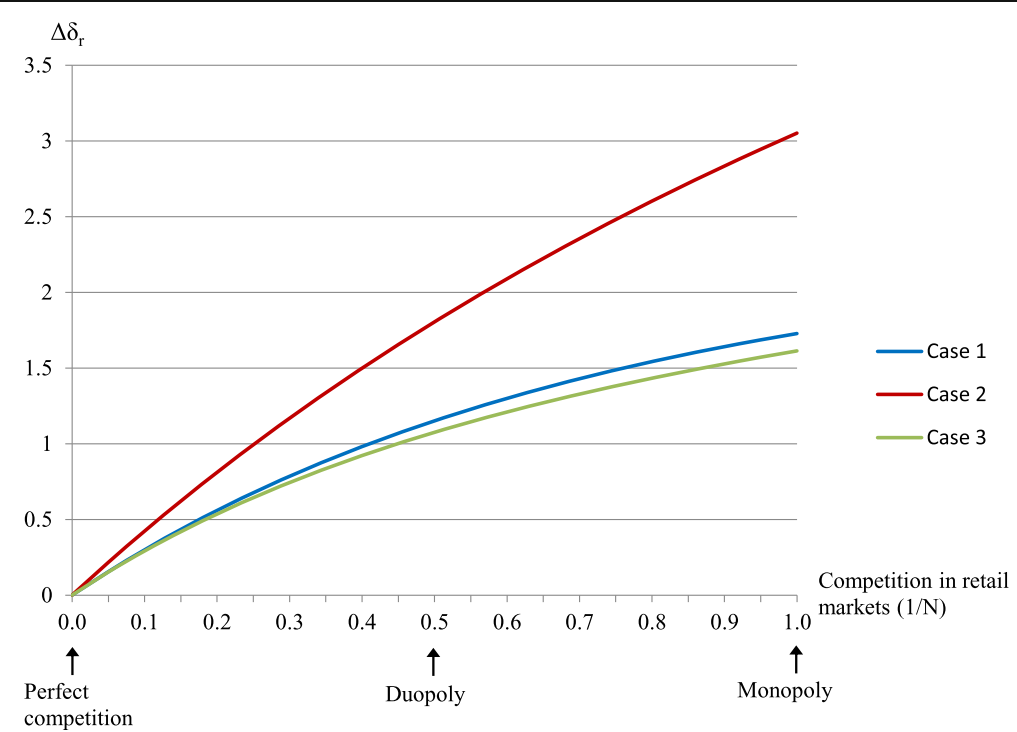

Fig. 2 The increase $\left(\Delta \delta_{r}\right)$ in retailers' profit margin due to the weakened buyer power in agricultural procurement under various levels of seller power in retail markets. Note: $\Delta \delta_{r}$ is the increase in retailers' profit margin when processors' buyer power is weakened from $M=2$ to $M=3$. The increase $\left(\Delta \delta_{r}\right)$ is larger when retailers have stronger seller power in retail markets. Case 1 is when there is a competitive wholesale market. Case 2 is when there is an oligopoly wholesale market. Case 3 is when there is an oligopsony wholesale market. Retailers' profit margin increase in case 2 (red line) is larger than that in case 1 (blue line). The relative magnitudes between retailers' profit margin increase in case 3 and those in cases 1 and 2 depend on various market factors so that all (in)equalities between them are possible

margin increases $\left(\Delta \delta_{r}>0\right)$ if buyer power in agricultural procurement is weakened, and the profit margin increase is larger when there is a higher degree of retailers' seller power.

Similarly, we can use the equilibrium retail price and processors' profit margin to analyze the case in which retailers' seller power is weakened. Proposition 2 includes the results.

Proposition 2 Although consumer welfare will gain and retail price will decrease if seller power in retail markets is weakened, the magnitude of the consumer welfare gain and retail price decrease is reduced by processors' buyer power. In addition, the anticompetitive effect of processors' buyer power will be enlarged, i.e., processors' profit margin will increase.

When processors have stronger buyer power in agricultural procurement, the consumer welfare gain and retail price decrease due to weakened seller power in retail markets will be smaller. The increase in processors' profit margin will be larger.

Proof Appendix.

The economic intuition of Proposition 2 is similar to the one of Proposition 1. Figures 3 and 4 show the simulation results for Proposition 2. The parameters used are the same as those in the simulation for Figs. 1 and 2. Seller power in food retailing is weakened from $N=2$ to $N=3$. The impact of wholesale market structures is also shown in Figs. 3 and 4 .

\section{Optimal allocation of anti-trust efforts}

The above two propositions show that addressing only one form of market power may be ineffective because the benefit will be offset by the other form of market power. 


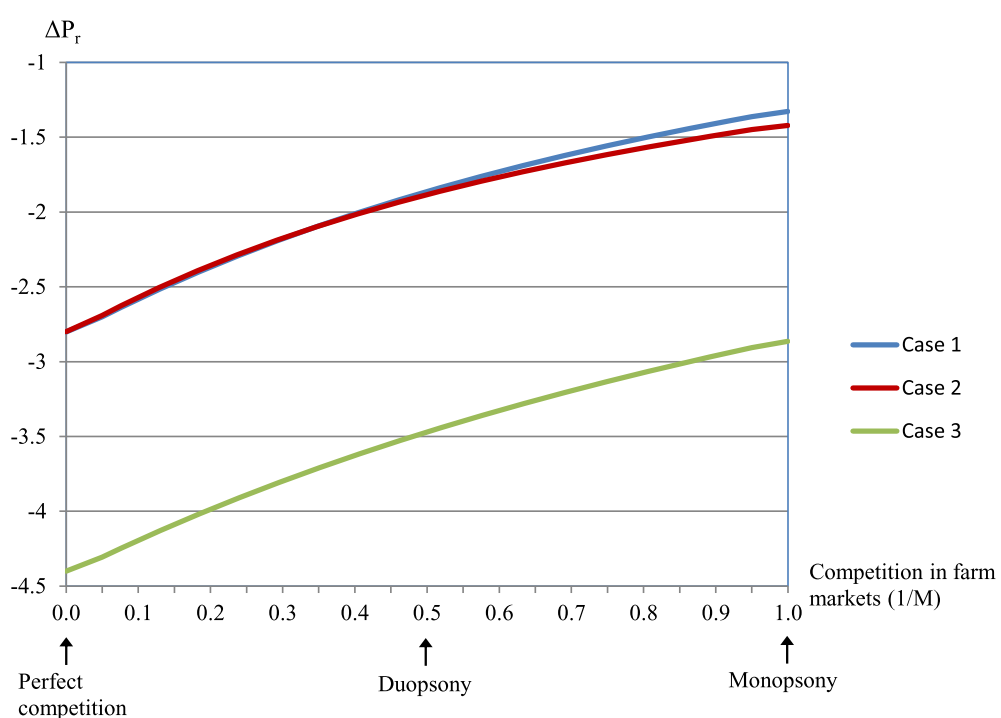

Fig. 3 Retail price decrease $\left(\Delta P_{r}\right)$ due to the weakened seller power in food retailing under various levels of buyer power in farm markets. Note: $\Delta P_{r}$ is the decrease in retail price when retailers' seller power is weakened from $N=2$ to $N=3$. The magnitude of decrease $\left(\left|\Delta P_{r}\right|\right)$ is smaller when the processors have stronger buyer power in farm markets. Case 1 is when there is a competitive wholesale market. Case 2 is when there is an oligopoly wholesale market. Case 3 is when there is an oligopsony wholesale market. Retail price decrease $\left(\mid \Delta P_{r}\right)$ in case 3 (green line) is larger than that in case 1 (blue line). The relative magnitudes between retail price decrease in case 2 and those in cases 1 and 3 depend on various market factors so that all (in)equalities between them are possible

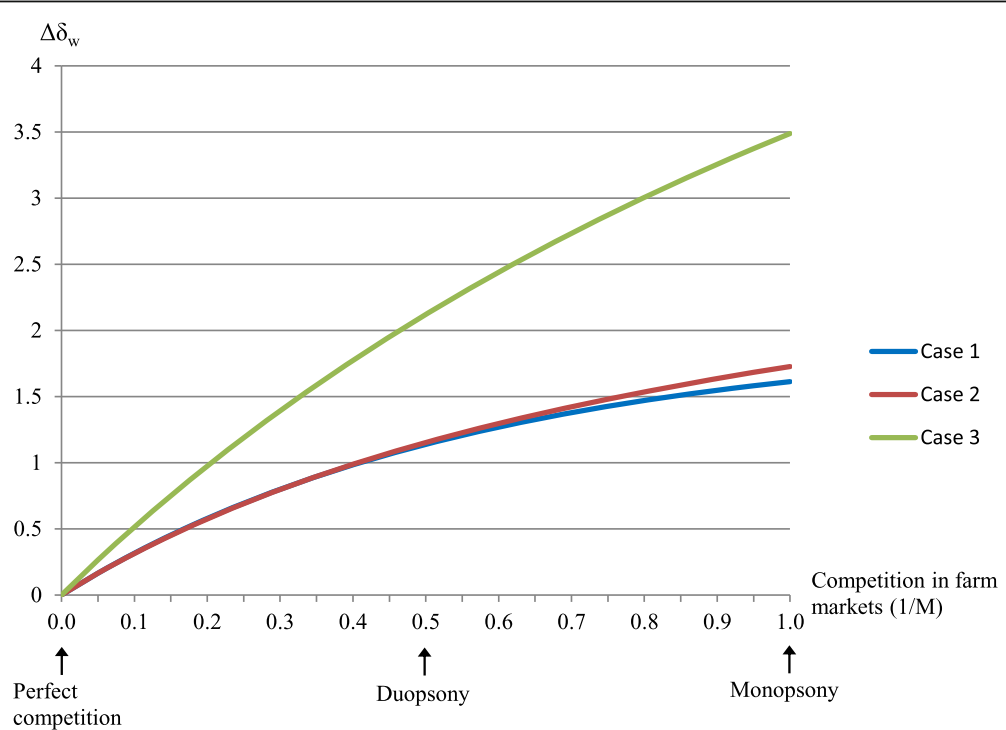

Fig. 4 The increase $\left(\Delta \delta_{w}\right)$ in processors' profit margin due to the weakened seller power in retail markets under various levels of buyer power in agricultural procurement. Note: $\Delta \delta_{w}$ is the increase in processors' profit margin when retailers' seller power is weakened from $N=2$ to $N=3$. The increase $\left(\Delta \delta_{w}\right)$ is larger when the processors have stronger buyer power in farm markets. Case 1 is when there is a competitive wholesale market. Case 2 is when there is an oligopoly wholesale market. Case 3 is when there is an oligopsony wholesale market. Processors' profit margin increase in case 3 (green line) is larger than that in case 1 (blue line). The relative magnitudes between processors' profit margin increase in case 2 and those in cases 1 and 3 depend on various market factors so that all (in)equalities between them are possible 
Dealing with both forms of market power in farm and retail markets means that more of the benefits from reducing market power will be enjoyed by the farmers and consumers. ${ }^{7}$ Thus, we analyze the optimal allocation of anti-trust efforts between farm and retail market that maximizes welfare and find the following results:

Proposition 3 Even if the policy objective is to maximize the welfare of price-takers in one stage of food market chain (e.g., farmers), anti-trust efforts may need to be allocated to both farm and retail markets rather than only the one stage (e.g., farm market). More importantly, the optimal allocations of anti-trust efforts are the same for these three different policy objectives: (i) to maximize farmer welfare, (ii) to maximize consumer welfare, and (iii) to maximize social welfare.

Proof Appendix.

Let us discuss the economic reason for the results in this proposition. Reducing market power through anti-trust efforts in one stage (e.g., retail market) benefits not only the price-takers (e.g., consumers) in this stage but also the market participants (e.g., farmers and processors) in another stage (e.g., farm market). Thus, a policymaker always wants to allocate anti-trust efforts to make sure that the marginal gain in welfare due to putting anti-trust efforts in one market is equal to the marginal gain due to putting efforts in another market, regardless of whether the objective is to maximize welfare of farmers only, consumers only, or the entire society.

Even if the policy objective is to maximize farmer welfare only, for each unit of anti-trust efforts, a policymaker can assign this unit to either the farm market, which will benefit farmers directly, or the retail market, which will benefit farmers indirectly through increased demand for farm product, depending on the relative magnitudes of these two benefits. At the equilibrium, the optimal allocation of anti-trust efforts to maximize farmer welfare may require a positive amount of anti-trust efforts in both farm and retail market, and the marginal gain in the welfare of anti-trust efforts is equal in the two markets.

For the three policy objectives (to maximize farmer welfare, consumer welfare, or social welfare), the optimal allocation of anti-trust efforts results in the largest increase in the quantity of products sold by farmers, or purchased by consumers, or that transacted in all markets. Because the agricultural/food product is produced, processed, and transacted along the supply chain and all stages are connected, an optimal allocation of anti-trust efforts that brings the largest increase in the amount of products sold by farmers will also cause the largest increase in the amount of products purchased by consumers and those transacted in all three (farm, wholesale, retail) markets. Therefore, the optimal allocations of anti-trust efforts are the same for all the three different policy objectives.

We also examine what factors and how they affect the optimal allocation of anti-trust efforts to maximize welfare, and the results are included in the following proposition:

Proposition 4 The results about the optimal shares of anti-trust efforts are:

(i) Given the amount of available anti-trust efforts, the optimal share of efforts allocated to farm market is increasing in the steepness of farm supply curve and processors' buyer power in farm market and decreasing in the steepness of consumer demand and retailers' seller power in the retail market. The optimal share of efforts allocated 
to retail market will have the exact opposite directions of changes in response to the changes in these four factors.

(ii) If the two effort functions, $E_{f}(\Delta M)$ and $E_{r}(\Delta N)$, have the same form, allocate more (less) than 50\% anti-trust efforts to farm market and the remaining effort to retail market if $b N^{2}>\beta M^{2}$ (if $\left.b N^{2}<\beta M^{2}\right)$.

(iii) In general, the optimal share of efforts can be calculated using farm supply and consumer demand functions, measures of market power in two markets, and specified anti-trust effort equations. The optimal share of efforts for farm market is represented as $E_{f}\left[\Psi^{-1}(0)\right] / \bar{E}$, and the optimal share for retail market is $1-E_{f}\left[\Psi^{-1}(0)\right] / \bar{E}$.

\section{Proof Appendix.}

In a market with steeper (or inelastic) supply or demand curve and stronger market power, the welfare loss due to market power is larger. Thus, more anti-trust efforts should be allocated in this market than in another market along the supply chain. Therefore, the optimal shares of anti-trust efforts allocated to farm and retail market depend on the relative magnitudes of the four factors, the steepness of farm supply curve, the steepness of consumer demand curve, processors' buyer power in farm market, and retailers' seller power in retail market, as indicated in Proposition 4.

\section{Conclusions}

Two forms of market power along the food market chain, buyer power in agricultural procurement and seller power in food retailing, have been discussed and examined extensively in the general press and academic research. However, little attention has been paid to the interaction between the two forms of market power and, especially, the optimal allocation of anti-trust efforts among farm and retail markets to maximize welfare. Understanding this issue is essential for taking appropriate and effective measures against anticompetitive behaviors in the agricultural and food sector.

The analysis in this paper shows that the benefit of weakening one form of market power is reduced by another form of market power in the food market chain so that it is necessary to address both forms of market power together. More importantly, to maximize farmer welfare, a policymaker may need to allocate anti-trust efforts to both farm and retail markets. The optimal allocations of anti-trust efforts are actually the same for three different policy objectives (to maximize farmer welfare, maximize consumer welfare, and maximize social welfare). The reason is that all these markets are vertically connected though the movement of one agricultural/food product so that addressing market power to improve welfare in one market will benefit other markets as well.

The optimal share of anti-trust efforts of farm (retail) market is increasing (decreasing) in the steepness of farm supply curve and processors' buyer power and decreasing (increasing) in the steepness of consumer demand curve and retailers' seller power. We also provide some guidelines and formula for the design and calculation of optimal allocations of anti-trust efforts among farm and retail markets. 
Table 1 The impact of various wholesale market structures on farm and retail price and processors' and retailers' profit

\begin{tabular}{|c|c|}
\hline & Impact of wholesale market structures \\
\hline Farm price increase $\left(\partial P_{f} / \partial M\right)$ & $\partial P_{f, \mathrm{OP}} / \partial M>\partial P_{f, \mathrm{c}} / \partial M$ \\
\hline Retail price decrease $\left(\left|\partial P_{r} / \partial N\right|\right)$ & $\left|\partial P_{r, ~ o s} / \partial N\right|>\left|\partial P_{r, ~ c M} / \partial N\right|$ \\
\hline $\begin{array}{l}\text { Processors' profit margin increase } \\
\left(\partial \delta_{w} / \partial N\right)\end{array}$ & $\partial \delta_{w,} \mathrm{OS} / \partial N>\partial \delta_{w, \mathrm{cM}} / \partial N$ \\
\hline $\begin{array}{l}\text { Retailers' profit margin increase } \\
\left(\partial \delta_{r} / \partial M\right)\end{array}$ & $\partial \delta_{r, \mathrm{OP}} / \partial M>\partial \delta_{r, \mathrm{c}} / \partial M$ \\
\hline Farm price $\left(P_{f}\right)$ & $P_{f, \mathrm{OP}}<P_{f, \mathrm{CM}}, P_{f, \mathrm{OS}}<P_{f, \mathrm{CM}}, P_{f, \mathrm{OP}} \lesseqgtr P_{f, \mathrm{OS}}$ \\
\hline Retail price $\left(P_{r}\right)$ & $P_{r, \text { OP }}>P_{r, \mathrm{CM}} P_{r, \text { OS }}>P_{r, \mathrm{CM}} P_{r, \text { OP }} \lesseqgtr P_{r, \text { OS }}$ \\
\hline Processors' profit margin $\left(\delta_{w}\right)$ & $\delta_{w, O P}>\delta_{w, C M}>\delta_{w, ~ O S}$ \\
\hline Retailers' profit margin $\left(\delta_{r}\right)$ & $\delta_{r, \mathrm{OP}}<\delta_{r, \mathrm{CM}}<\delta_{r, \mathrm{OS}}$ \\
\hline
\end{tabular}

Subscripts "CM," "OP," and "OS" denote competitive, oligopoly, and oligopsony wholesale market, respectively. " $>$ " indicates that the relative magnitudes depend on various market factors so that all (in)equalities between the two prices/ profit margins are possible

These findings can help improve the understanding on the nature of imperfect competition and optimal allocation of anti-trust efforts along the food market chain. Given that both buyer power in agricultural procurement and seller power in retail markets may exist for many agricultural and food industries, these findings are also useful for designing effective policies to promote competition in the agricultural and food sector.

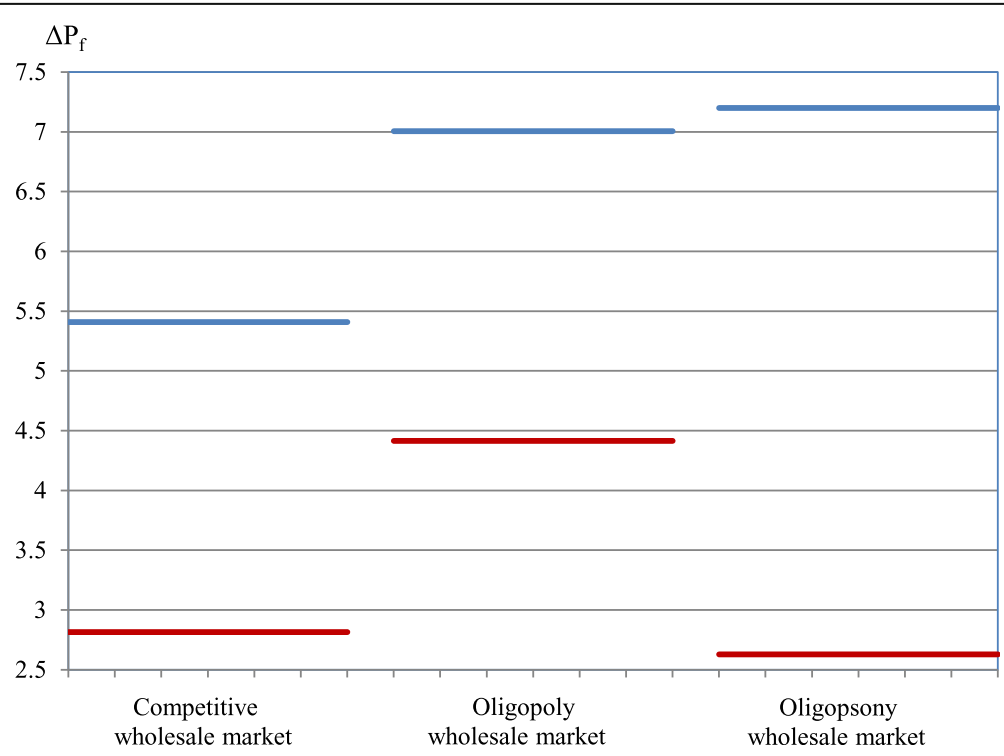

Fig. 5 Farm price increase $\left(\Delta P_{f}\right)$ in two scenarios of anti-trust methods under various wholesale market structures. Note: The red lines represent the farm price increase $\left(\Delta P_{f}\right)$ when only processors' buyer power is weakened (from $M=2$ to $M=3$ ). The blue lines represent the farm price increase $\left(\Delta P_{f}\right)$ when both processors' buyer power (from $M=2$ to $M=3$ ) and retailers' seller power are weakened (from $N=2$ to $N=3$ ). The farm price increases (blue lines) are larger when the two forms of market power are jointly addressed 


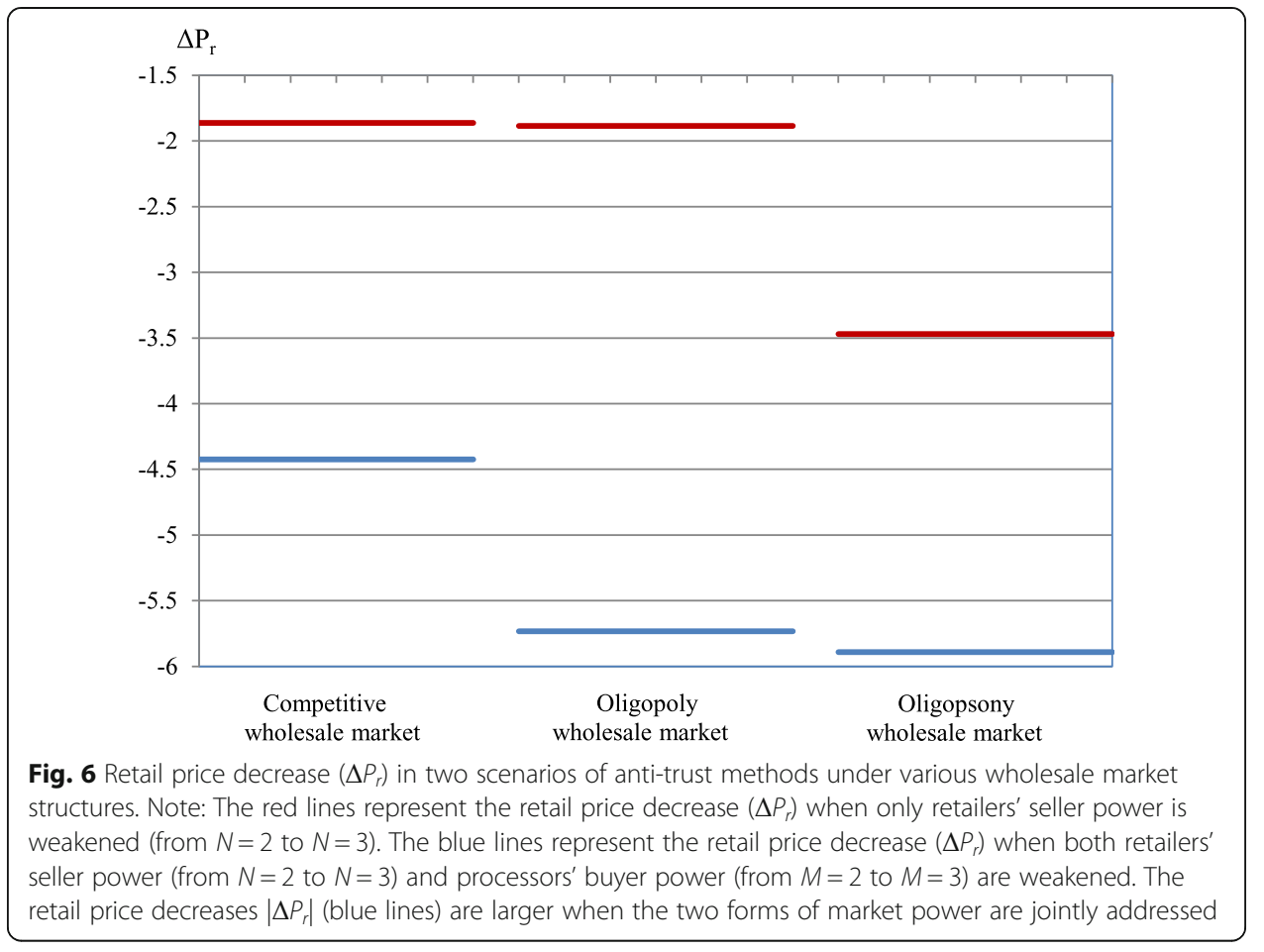

\section{Endnotes}

${ }^{1}$ Schroeter (1988) and Azzam and Pagoulatos (1990) measure the price distortion of monopsony and monopoly power in fed cattle and beef markets. Alston et al. (1997) analyze how both oligopsony power in buying raw farm product and oligopoly power in selling processed product affect the size of distribution of research benefits. Sexton (2000) examines the effects of oligopsony and oligopoly power on the distribution of welfare from agricultural producers and consumers to processors/retailers possessing market power.

${ }^{2}$ We use the number of firms to represent market power in order to facilitate the analysis. When firms are modeled as symmetric and have equal market share in Cournot competition, as in this paper's analysis, the number of firms can provide a measure for firm profitability and market competitiveness. But one needs to be careful and use it only when the number of firms is exogenous, i.e., not depending on the cost of entry (Tirole 1988, p. 222). In addition, market power is more often represented based on a conjectural elasticity that affects the markup as in Sexton et al. (2007).

${ }^{3}$ In addition, we analyze the cases of an oligopoly and oligopsony wholesale market and found that all qualitative results discussed in this paper also hold in those two cases. Table 1 and the figures help compare and illustrate the results of the three cases of wholesale market structures.

${ }^{4}$ We assume a constant average and marginal cost in the three markets to facilitate exposition. The qualitative results will hold when a general convex cost curve is used.

${ }^{5}$ The condition $\lambda-C_{r}-C_{w}-a>0$ is assumed to guarantee that gain from trade exists in food market chain, which means that the highest consumer reservation price is larger than the sum of production, processing, and retailing costs. 
${ }^{6} \mathrm{~A}$ pivotal shift of the wholesale demand or supply makes the slope steeper and keeps the intercept on the price axis unchanged.

${ }^{7}$ Figures 5 and 6 illustrate that dealing both forms of market power results in more benefits to farmers and retailers through simulations. The functions and parameters in the simulations are the same as those in previous simulations.

\section{Appendix}

\section{Proof of propositions}

\section{Proof of Proposition 1}

Using the farm equilibrium price and the condition $\lambda-C_{r}-C_{w}-a>0$, we find

$$
\partial \mathrm{PS} / \partial M=b^{2} M N^{3}\left(\lambda-C_{r}-C_{w}-a\right)^{2} /[b N(M+1)+\beta M(N+1)]^{3}>0 \text { and }
$$

$\partial P_{f} / \partial M=b^{2} N^{2}\left(\lambda-C_{r}-C_{w}-a\right) /[b N(M+1)+\beta M(N+1)]^{2}>0$. So, farmer welfare will

be higher, and farmers will receive a higher price when buyer power in farm markets is weakened. We also obtain:

$$
\begin{aligned}
& \partial\left(\partial P_{f} / \partial M\right) / \partial N=2 b^{2} N \beta M\left(\lambda-C_{r}-C_{w}-a\right) /[b N(M+1)+\beta M(N+1)]^{3}>0 \text { and } \\
& \partial(\partial \mathrm{PS} / \partial M) / \partial N=\left[\left(\partial P_{f} / \partial N\right)\left(\partial P_{f} / \partial M\right)+\left(P_{f}-a\right)\left(\partial\left(\partial P_{f} / \partial M\right) / \partial N\right)\right] / b>0 .
\end{aligned}
$$

Thus, seller power in retail markets reduces the benefit to farmers of weakening buyer power in farm markets.

We use Eq. (4) to obtain:

$\partial \delta_{r} / \partial M=b N \beta\left(\lambda-C_{r}-C_{w}-a\right) /[b N(M+1)+\beta M(N+1)]^{2}>0$. Thus, the retailers' profit margin $\left(\delta_{r}\right)$ has actually increased when buyer power in farm markets is weakened.

Using the equilibrium farm price and eq. (4), we find

$$
\begin{aligned}
\partial^{2}\left(\partial P_{f} / \partial M\right) / \partial N^{2}= & -2 b^{2} \beta M\left(\lambda-C_{r}-C_{w}-a\right)[2 b N(M+1)+\beta M(2 N-1)] \\
& \times[b N(M+1)+\beta M(N+1)]^{-4}<0
\end{aligned}
$$

and

$$
\begin{aligned}
\partial\left(\partial \delta_{r} / \partial M\right) / \partial N= & -b \beta\left(\lambda-C_{r}-C_{w}-a\right)[b N(M+1)+\beta M(N-1)] \\
& \times[b N(M+1)+\beta M(N+1)]^{-3}<0 .
\end{aligned}
$$

So, when there is a higher degree (a smaller $N$ ) of seller market power in retail markets, the farm price increase due to weakened buyer power in agricultural procurement will be smaller, and the weakening of buyer power in agricultural procurement will cause a larger increase in retailers' profit margin.

\section{Proof of Proposition 2}

Using the equilibrium retail price and the condition $\lambda-C_{r}-C_{w}-a>0$, we find $\partial C S / \partial N=\beta^{2} N M^{3}\left(\lambda-C_{r}-C_{w}-a\right)^{2} /[b N(M+1)+\beta M(N+1)]^{3}>0$ and $\partial P_{r} / \partial N=-\beta^{2} M^{2}\left(\lambda-C_{r}-C_{w}-a\right) /[b N(M+1)+\beta M(N+1)]^{2}<0$. So, consumer welfare will be higher, and consumers will pay a lower price when seller power in retail markets is weakened. We also obtain:

$$
\begin{aligned}
& \partial\left(\partial P_{f} / \partial N\right) / \partial M=-2 b N \beta^{2} M\left(\lambda-C_{r}-C_{w}-a\right) /[b N(M+1)+\beta M(N+1)]^{3}<0 \text { and } \\
& \partial(\partial C S / \partial N) / \partial M=\left[\left(\partial P_{r} / \partial M\right)\left(\partial P_{r} / \partial N\right)-\left(\lambda-P_{r}\right)\left(\partial\left(\partial P_{r} / \partial N\right) / \partial M\right)\right] / \beta>0 .
\end{aligned}
$$

Thus, buyer power in agricultural procurement reduces the benefit $\left(\left|\partial P_{r} / \partial N\right|\right.$ and $\partial \mathrm{CS} / \partial N)$ to consumers of weakening seller power in retail markets.

We use Eq. (3) to find: 
$\partial \delta_{w} / \partial N=b \beta M\left(\lambda-C_{r}-C_{w}-a\right) /[b N(M+1)+\beta M(N+1)]^{2}>0$. Thus, processors' profit margin $\left(\delta_{w}\right)$ has actually increased when seller power in retail markets is weakened.

Using the equilibrium retail price and Eq. (3), we find:

$$
\begin{aligned}
\partial^{2}\left(\partial P_{r} / \partial N\right) / \partial M^{2} & =2 b \beta^{2} N\left(\lambda-C_{r}-C_{w}-a\right)[b N(2 M-1)+2 \beta M(N+1)] \\
& \times[b N(M+1)+\beta M(N+1)]^{-4}>0
\end{aligned}
$$

and

$$
\begin{aligned}
\partial\left(\partial \delta_{w} / \partial N\right) / \partial M= & -b \beta\left(\lambda-C_{r}-C_{w}-a\right)[b N(M-1)+\beta M(N+1)] \\
& \times[b N(M+1)+\beta M(N+1)]^{-3}<0
\end{aligned}
$$

So, when there is a higher degree (a smaller $M$ ) of buyer market power in farm markets, the retail price decrease due to weakened seller power in retail markets will be smaller, and the weakening of seller power in retail markets will cause a larger increase in processors' profit margin.

\section{Optimal allocation of anti-trust efforts}

Proof of Proposition 3

A policymaker's problem to maximize consumer welfare is:

$$
\begin{aligned}
& \operatorname{Max}_{E_{f}, E_{r}} \Delta \mathrm{CS} \\
& \text { s.t. } E_{f}+E_{r}=\bar{E},
\end{aligned}
$$

where $\Delta C S$ is the gain in consumer surplus due to the anti-trust efforts. Using the solution of $\Delta N$ and the equilibrium result of consumer surplus, we find the consumer welfare gain as:

$$
\begin{aligned}
\Delta C S \approx(\partial C S / \partial M) \Delta M & +(\partial C S / \partial N) \Delta N \\
& =\beta M N\left[b N^{2} \Delta M\right]+\beta M^{2} \Phi^{-1}(0)\left(\lambda-C_{r}-C_{w}-a\right)^{2} \\
& /[b N(M+1)+\beta M(N+1)]^{3}
\end{aligned}
$$

Solving the first-order condition $\partial \Delta \mathrm{CS} / \partial \Delta M=0$ for $\Delta M$ and substituting the solution of $\Delta M$ into the anti-trust effort equation yields the optimal allocation of anti-trust efforts as:

$$
E_{f}=E_{f}\left[\Psi^{-1}(0)\right]
$$

and

$$
E_{r}=\bar{E}-E_{f}\left[\Psi^{-1}(0)\right]
$$

In order to maximize the total social welfare, a policymaker's problem is:

$$
\begin{gathered}
\operatorname{Max}_{E_{f}, E_{r}} \Delta \mathrm{SW} \\
\text { s.t. } E_{f}+E_{r}=\bar{E},
\end{gathered}
$$

where $\Delta \mathrm{SW}$ is the gain in social welfare due to the anti-trust efforts. Using the solution of $\Delta N$ and the equilibrium result of social welfare, we find the social welfare gain as: 


$$
\begin{aligned}
\Delta \mathrm{SW} \approx(\partial \mathrm{SW} / \partial M) \Delta M & +(\partial \mathrm{SW} / \partial N) \Delta N \\
& =(b N+\beta M)\left[b N^{2} \Delta M+\beta M^{2} \Phi^{-1}(0)\right]\left(\lambda-C_{r}-C_{w}-a\right)^{2} \\
& /[b N(M+1)+\beta M(N+1)]^{3}
\end{aligned}
$$

Solving the first-order condition $\partial \Delta \mathrm{SW} / \partial \Delta M=0$ for $\Delta M$ and substituting the solution of $\Delta M$ into the anti-trust effort equation yields the optimal allocation of anti-trust efforts as:

$$
E_{f}=E_{f}\left[\Psi^{-1}(0)\right]
$$

and

$$
E_{r}=\bar{E}-E_{f}\left[\Psi^{-1}(0)\right]
$$

The optimal values of $E_{f}$ and $E_{r}$ in the three welfare maximization problems show that the optimal allocations of anti-trust efforts are the same for the three different policy objectives: (i) to maximize farmer welfare, (ii) to maximize consumer welfare, and (iii) to maximize social welfare.

The derived optimal allocation of anti-trust efforts for farm market is:

$$
E_{f}=E_{f}\left[\Psi^{-1}(0)\right]
$$

where $\Psi^{-1}(\bullet)$ is the inverse function of $\Psi(\bullet)$ and

$\Psi(\Delta M)=b N^{2}+\beta M^{2}\left[\partial \Phi^{-1}(0) / \partial \Delta M\right]$ with $\partial \Phi^{-1}(0) / \partial \Delta M<0$. For certain functional forms of the effort equations such as $E_{f}(\Delta M)=\theta(\Delta M)^{2}$ and $E_{r}(\Delta N)=\theta(\Delta N)^{2}$, interior solutions of $\Delta M$ and $\Delta N$ are possible, which means both $\Delta M>0$ and $\Delta N>0$. Thus, the optimal values of $E_{f}$ and $E_{r}$ can be positive, and the anti-trust efforts should be allocated to both farm and retail market in order to maximize welfare.

\section{Proof of Proposition 4}

Using implicit functional theorem, $\Psi(\Delta M)=b N^{2}+\beta M^{2}\left[\partial \Phi^{-1}(0) / \partial \Delta M\right]$ with $\partial \Phi^{-1}(0) /$ $\partial \Delta M<0$, and the second-order condition

$\partial \Psi(\Delta M) / \partial \Delta M=\partial^{2} \Phi^{-1}(0) / \partial(\Delta M)^{2}<0$, we obtain $\partial \Delta M / \partial b>0, \partial \Delta M / \partial N>0, \partial \Delta M / \partial \beta<0$, and $\partial \Delta M / \partial M<0$. Because $\partial E_{f} / \partial \Delta M>0$, then we have the optimal allocation of efforts to farm market is increasing in the steepness $(b)$ of farm supply curve and processors' buyer power $(1 / M)$ in farm market and decreasing in the steepness $(\beta)$ of consumer demand curve and retailers' seller power $(1 / N)$ in retail market.

If the two effort functions, $E_{f}(\Delta M)$ and $E_{r}(\Delta N)$, have the same form, we derive:

$$
E_{r}=E_{r}\left[\Gamma^{-1}(0)\right],
$$

where $\Gamma^{-1}(\bullet)$ is the inverse function of $\Gamma(\bullet)$ and

$\Gamma(\Delta N)=\beta M^{2}+b N^{2}\left[\partial \Phi^{-1}(0) / \partial \Delta N\right]$ with $\partial \Phi^{-1}(0) / \partial \Delta N<0$. Using the functions $\Gamma(\Delta N)$ and $\Psi(\Delta M)$, the concept of inverse function and the implicit functional theorem, we find that if $b N^{2}>\beta M^{2}$ holds, we have $\Psi^{-1}(0)>\Gamma^{-1}(0), E_{f}>E_{n}$ and $E_{f}>50 \% \bar{E}$. Similarly, if $b N^{2}<\beta M^{2}$ holds, we have $\Psi^{-1}(0)<\Gamma^{-1}(0), E_{f}<E_{n}$ and $E_{f}<50 \% \bar{E}$.

In general, the optimal share of anti-trust efforts in the farm market is calculated as the optimal amount of effort divided by total amount effort, i.e., $E_{f}\left[\Psi^{-1}(0)\right] / \bar{E}$. The rest of the efforts is allocated to the retail market. So, the optimal share of efforts for the retail market is $1-E_{f}\left[\Psi^{-1}(0)\right] / \bar{E}$. 


\section{Acknowledgements}

The authors gratefully acknowledge the valuable suggestions from two anonymous referees and the editor and helpful comments of colleagues and participants of AAEA Annual Meetings.

\section{Availability of data and materials}

All detailed derivation process and theoretical and simulation results in the analysis are available from the authors upon request.

\section{Authors' contributions}

TX contributed to the conceptual model and the simulation analysis. BS contributed to the simulation analysis. Both authors read and approved the final manuscript.

\section{Competing interests}

The authors declare that they have no competing interests.

\section{Publisher's Note}

Springer Nature remains neutral with regard to jurisdictional claims in published maps and institutional affiliations.

Received: 17 February 2017 Accepted: 13 July 2018

Published online: 22 August 2018

\section{References}

Alston JM, Sexton RJ, Zhang M (1997) The effects of imperfect competition on the size and distribution of research benefits. Am J Agric Econ 79:1252-1265

Alvarez AM, Fidalgo EG, Sexton RJ, Zhang M (2000) Oligopsony power with uniform spatial pricing: theory and application to milk processing in Spain. Eur Rev Agric Econ 27:347-364

Azzam AM (1999) Asymmetry and rigidity in farm-retail price transmission. Am J Agric Econ 81:525-533

Azzam AM, Anderson D (1996) Assessing competition in meatpacking: economic history, theory and evidence. U.S. Department of Agriculture, GIPSA-RR, Washington D.C., pp 96-96

Azzam AM, Pagoulatos E (1990) Testing oligopolistic and oligopsonistic behavior: an application to the U.S. meatpacking industry. J Agric Econ 41:362-370

Benson B, Faminow M (1985) An alternative view of pricing in retail food markets. Am J Agric Econ 67:298-306

Boatwright P, Dhar S, Rossi P (2004) The role of retail competition and account retail strategy as drivers of promotional sensitivity. Quant Mark Econ 2:169-190

Davis D (2010) Price and promotion effects of supermarket mergers. J Agric Food Ind Organ 8:8

Declerck F, Fourcadet O, Faucher H (1999) Forward contract versus spot market: the case of the French beef chain. In: Galizzi G, Venturini L (eds) Vertical Relationships and Coordination in the Food System. Physica-Verlag, Heidelberg

Digal N (2010) Market power analysis: the case of poultry industry in the Philippines. J Int Food Agribusiness Mark 23:5-31

Draganska M, Klapper D, Villas-Boas SB (2010) A larger slice or a larger pie? An empirical investigation of bargaining power in the distribution channel. Mark Sci 29:57-74

Durham CA, Sexton RJ (1992) Oligopsony potential in agriculture: residual supply estimation in California's processing tomato market. Am J Agric Econ 74:962-972

Farina EMMQ, Nunes R, de Monteiro GF A (2004) Modeling produce procurement and merchandising strategies of traditional retailers in the face of competition with supermarkets in the São Paulo region. Paper presented at 88th Seminar of the EAAE, Paris

Hosken D, Reiffen D (2004) Patterns of retail price variation. RAND J Econ 35:128-146

Huang S, Sexton RJ (1996) Measuring returns to an innovation in an imperfectly competitive market: application to mechanical harvesting of processing tomatoes in Taiwan. Am J Agric Econ 78:558-571

Katz M (1989) Vertical contractual relations. In: Schmalensee R, Willig RD (eds) Handbook of industrial organization, vol I. North-Holland, Amsterdam, pp 655-721

Lal R, Rao R (1997) Supermarket competition: the case of every day low pricing. Mark Sci 16:60-80

Lloyd T, McCorriston S, Morgan W, Rayner A, Weldegebriel H (2009) Buyer power in U.K. food retailing: a 'first-pass' test. J Agric Food Ind Org 7:5

McEowen RA, Carstensen PC, Harl NE (2002) The 2002 Senate Farm Bill: the ban on packer ownership of livestock. Drake J Agric Law 7:267-304

Pesendorfer M (2002) Retail sales: a study of pricing behavior in supermarkets. J Bus 75:33-66

Phlips L (1980) Intertemporal price discrimination and sticky prices. Q J Econ 94:525-542

Raper KC, Love AH, Shumway CR (2000) Determining market power exertion between buyers and sellers. J Appl Econ 15:225-252

Richards, T. and P. Patterson. "Competition in fresh produce markets: an empirical analysis of marketing channel performance," Economic Research Service, U.S. Department of Agriculture, Contractors and Cooperators Report No. 1, 2003

Schroeter JR (1988) Estimating the degree of market power in the beef packing industry. Rev Econ Stat 70:158-162

Schroeter JR, Azzam AM, Zhang M (2000) Measuring market power in bilateral oligopoly: the wholesale market for beef. South Econ J 66:526-547

Sexton RJ (2000) Industrialization and consolidation in the U.S. food sector: implications for competition and welfare. Am J Agric Econ 82:1087-1104

Sexton RJ, Sheldon I, McCorrison S, Wang H (2007) Agricultural trade liberalization and economic development: the role of downstream market power. Agric Econ 36:253-270 
Sexton, R. J., M. Zhang, and J. M. Chalfant. "Grocery retailer behavior in the procurement and sale of perishable fresh produce commodities," Economic Research Service, U.S. Department of Agriculture, Contractors and Cooperators Report No. 2, 2003

Spengler JJ (1950) Vertical integration and antitrust policy. J Polit Econ 50:347-352

Stiegert KM, Hamilton SF (1998) Backward implicit contracts, pre-commitment and market power in the international durum wheat market. Selected Paper, the American Agricultural Economics Association's Annual Meeting, Salt Lake City

Tirole J (1988) The theory of industrial organization. MIT press, Cambridge

U.S. Department of Agriculture, Economic Research Service. The U.S. food marketing system: recent developments, 1997-2006. 2007

U.S. Department of Agriculture, Economic Research Service. Topics/food markets \& prices/retailing \& wholesaling, 2007b, 2012.

U.S. Department of Agriculture, Grain Inspection Packers and Stockyards Administration. 2016 annual report: packers and stockyards program; 2016.

U.S. Department of Justice. Competition and agriculture: voice form the workshops on agriculture and antitrust enforcement in our $21^{\text {st }}$ century economy and thoughts on the way forward. 2012. Available at http://www.justice gov/atr/public/reports/283291.pdf

Varian H (1980) A model of sales. Am Econ Rev 70:651-659

Volpe R (2013) Promotional competition between supermarket chains. Rev Ind Organ 42:45-61

Walden M (1990) Testing implications of spatial economics models: some evidence from food retailing. J Consum Aff 24:24-43

Ward CE (2002) A review of causes for and consequences of economic concentration in the U.S. meatpacking industry. Curr Agric Food Resour Issues 3:1-28

Wilcox MD, Abbott PC (2006) Can cocoa farmer organizations countervail buyer market power? Selected Paper, the American Agricultural Economics Association's Annual Meeting, Long Beach

Zhang M, Sexton RJ (2000) Captive supplies and the cash market price: a spatial markets approach. J Agric Resour Econ 25:88-108

Zheng X, Vukina T (2009) Do alternative marketing arrangements increase pork packers' market power? Am J Agric Econ 91:250-263

Submit your manuscript to a SpringerOpen ${ }^{0}$ journal and benefit from:

- Convenient online submission

- Rigorous peer review

- Open access: articles freely available online

High visibility within the field

- Retaining the copyright to your article

Submit your next manuscript at $\boldsymbol{\nabla}$ springeropen.com 